\title{
The Effect of Fetal Breathing Movements on Pulmonary Blood Flow in Fetal Sheep
}

\author{
RENATE D. SAVICH, ${ }^{1}$ FRANCISCO A. GUERRA, ${ }^{2}$ CHU-CHING H. LEE, AND \\ JOSEPH A. KITTERMAN \\ Cardiovascular Research Institute and Department of Pediatrics, University of California, San Francisco, \\ San Francisco, California 94143
}

\begin{abstract}
In the fetus, normal lung growth requires both fetal breathing movements (FBM) and adequate pulmonary blood flow. We postulated that FBM intermittently increase pulmonary blood flow and may stimulate lung growth through that effect. To test the hypothesis that normal intermittent FBM cause associated intermittent increases in pulmonary blood flow, we studied eight chronically instrumented fetal sheep (gestational ages 125-143 d) on 34 occasions (total study time $=65.7 \mathrm{~h}$ ). Each fetus had a cuff electromagnetic flow transducer around the left pulmonary artery, electrocortical electrodes, and catheters in the trachea, main pulmonary artery, carotid artery, and amniotic cavity. Mean blood flow though the left pulmonary artery averaged $59 \pm 8 \mathrm{~mL} / \mathrm{min}$ (mean \pm SEM; per $\mathrm{kg}: 25 \pm 4 \mathrm{~mL} / \mathrm{kg} / \mathrm{min}$ ) and was similar in both the presence $(61 \pm 9 \mathrm{~mL} / \mathrm{min})$ and absence $(57 \pm 7 \mathrm{~mL} / \mathrm{min})$ of FBM and during both high and low voltage electrocortical activity. In contrast, in utero phasic pulmonary blood flow varied with FBM, increasing during the inspiratory phase and decreasing during the expiratory phase. Both pulmonary and systemic vascular pressures showed changes in the opposite directions. Arterial pH and blood gas tensions were normal and did not change with FBM or electrocortical activity. We conclude that FBM do not increase mean blood flow through the left pulmonary artery; thus, it is unlikely that FBM stimulate lung growth through changes in pulmonary blood flow. (Pediatr Res 35:484-489, 1994)
\end{abstract}

\section{Abbreviations}

ECoG, electrocortical activity

FBM, fetal breathing movement

HV-ECoG, high-voltage electrocortical activity

LV-ECoG, low-voltage electrocortical activity

QLPA, blood flow to left pulmonary artery

In the fetus, normal lung growth is dependent on several factors including (I) FBM of normal incidence and amplitude, and (2)

Received April 9, 1993; accepted November 19, 1993.

Correspondence and reprint requests: Renate D. Savich, M.D., Department of Pediatrics, 3rd Floor A.C.C., University of New Mexico School of Medicine, Albuquerque, NM 87131.

Supported by USPHS Grant HL-27356 (Pulmonary SCOR). R.D.S. was supported by a Perinatology Training Grant. NIH HD07162, and a grant from the California Research and Medical Education Fund, American Lung Association of California. F.A.G. was supported by International Fellowship 1-F05-TW03768, Fogarty International Center, and Instituto de Fisiologia and Instituto de Obstetricia y Ginecologia, Universidad Austral de Chile.

'Current address: Department of Pediatrics, University of New Mexico School of Medicine, Albuquerque, NM 87131.

${ }^{2}$ Current address: Instituto de Fisiologia, Universidad Austral de Chile, P.O. Box 567, Valdivia, Chile. an adequate amount of blood flow to the lungs. The absence of FBM results in pulmonary hypoplasia (1-4). Changes in blood flow to an organ are also known to affect its subsequent growth; ligation of the left pulmonary artery in fetal sheep significantly decreases ipsilateral lung growth (5). Previous studies in stressed fetal lambs indicate that FBM and pulmonary blood flow may be interrelated; hypoxia decreases both $\operatorname{FBM}(6,7)$ and pulmonary blood flow $(8,9)$. In contrast, during respiratory acidosis, both FBM and pulmonary blood flow are increased (10-13).

Postnatally, breathing affects pulmonary blood flow; the inspiratory phase causes an increase in venous return and a subsequent increase in pulmonary blood flow (14). However, it is not clear whether this relationship is similar in utero during normal FBM and how these FBM affect overall pulmonary blood flow. Therefore, the purpose of this study was to evaluate the possible interrelationships of two factors known to be essential for fetal lung growth, namely, FBM and pulmonary blood flow. We hypothesized that normal intermittent FBM cause associated intermittent increases in pulmonary blood flow. To test this hypothesis, we studied the relationships of spontaneously occurring $\mathrm{FBM}$ and pulmonary blood flow under normal conditions using chronically instrumented fetal sheep in which an electromagnetic flow transducer had been placed around the left pulmonary artery.

\section{MATERIALS AND METHODS}

We studied eight fetal sheep that were products of Western Breed ewes mated with Blackfaced rams. All studies were approved by the Committee on Animal Research of the University of California, San Francisco.

Surgical preparation. We operated on the fetuses at gestational ages of 124 to $129 \mathrm{~d}$; term is 145 to $150 \mathrm{~d}$. After a fast of $24 \mathrm{~h}$, the ewe was sedated with ketamine $(10 \mathrm{mg} / \mathrm{kg})$ and the ewe and fetus were then given general anesthesia with $1 \%$ halothane in oxygen. During the operative procedure, the ewe was mechanically ventilated through an endotracheal tube using a Harvard animal respirator (Harvard Apparatus Co., Dover, MA). Using sterile technique, we exposed the fetal upper body through a midline abdominal hysterotomy. Through an incision in the fetal neck, we inserted polyvinyl catheters (ID 0.04 inches, length 100 $\mathrm{cm}$ ) into a carotid artery and into the trachea $3 \mathrm{~cm}$ below the thyroid cartilage. The neck incision was then closed.

Through an incision in the left fourth intercostal space, we exposed the main and left pulmonary arteries. A cuff electromagnetic flow transducer (3.5 to $4.5 \mathrm{~mm}$; $\mathrm{C}$ and $\mathrm{C}$ Instruments, Culver City, CA; or Statham Instruments, Oxnard, CA) was fitted around the left pulmonary artery; the transducer caused a mild constriction of no more than $10 \%$ of the diameter of the left pulmonary artery. The position of the flow transducer was stabilized by suturing the cable to a rib and the chest wall. A short catheter (Angiocath, 20-gauge, Becton-Dickinson, Rutherford, NJ) was inserted into the main pulmonary artery and 
sutured in place; the end of this catheter was firmly attached to a polyvinyl catheter (ID 0.04 inches, length $100 \mathrm{~cm}$ ) with cyclohexanone. The fetal chest was then sutured closed in layers.

Biparietal stainless steel electrodes were placed on the dura and secured as previously described (15). A fluid-filled, balloontipped catheter (ID 0.06 inches, length $100 \mathrm{~cm}$ ) was inserted into the amniotic cavity. The catheters, the cables from the flow transducer, and the dural electrodes were exteriorized through an incision in the ewe's flank and sutured to the skin of the flank. The catheters were filled with a solution of sodium chloride $(154 \mathrm{mmol} / \mathrm{L})$, heparin $(10000 \mathrm{U} / \mathrm{L})$, and ampicillin $(1 \mathrm{~g} / \mathrm{L})$. After recovery from anesthesia, the ewe was placed in a metabolic cage and fed ad libitum. She was given daily intramuscular injections of penicillin (1 million $\mathrm{U})$ and streptomycin $(1.25 \mathrm{~g})$ for the first 5 postoperative $d$.

Measurements. Fetal systemic and pulmonary arterial blood pressures were measured via the catheters in the carotid artery and the main pulmonary artery, respectively. The tracheal pressure tracing was used to record FBM; artifacts were identified by comparison of tracheal pressure with amniotic pressure. In this study, FBM refer only to multiple $(1-4 \mathrm{~Hz})$, rapid negative deflections in tracheal pressure greater than $2 \mathrm{~mm} \mathrm{Hg}$ in amplitude and lasting at least $20 \mathrm{~s}$, as previously defined by others (16). Infrequent (less than $4 / \mathrm{min}$ ), isolated negative pressure deflections (gasps) were not included in the analysis. Pressures were measured using P23Db transducers (Statham Instruments, Hato Ray, PR) positioned at the level of the maternal midabdomen; all pressures were referenced to amniotic pressure. Fetal ECoG was measured from the dural electrodes using a 7P5 preamplifier (Grass Instruments, Quincy, MA). ECoG was considered to be low in voltage when it was less than $40 \mu \mathrm{V}(17)$ and was considered high in voltage when it was greater than $40 \mu \mathrm{V}$. The ECoG was filtered with the low frequencies reduced to $1 / 2$ amplitude at $1 \mathrm{~Hz}$; high frequencies were not filtered. The actual frequencies of the ECoG signal were not measured; ECoG was differentiated on the basis of amplitude.

$Q_{\text {LPA }}$ was measured by connecting the flow transducer to a flow meter (SP2202, Statham Instruments, Oxnard, CA). Before the operative procedures, the flow transducers and flow meter were calibrated in vitro using directly measured flows of saline solution ( $154 \mathrm{mmol} / \mathrm{L})$; output was linear for flows between 20 and $300 \mathrm{~mL} / \mathrm{min}$. Electronic zero flow was frequently checked during the study and the baseline showed little drift; full-scale deflection was $320 \mathrm{~mL} / \mathrm{min}$. All pressures, pulmonary blood flow, and ECoG were recorded on a recorder (model 7 polygraph, Grass Instruments) at a paper speed of $15 \mathrm{~cm} / \mathrm{min}$. To evaluate individual wave forms, the paper speed was increased to 150 $\mathrm{cm} / \mathrm{min}$. Mean values for blood pressure and pulmonary blood flow were obtained by electrical integration; fetal heart rate was counted from the arterial pressure tracing.

Blood samples from the carotid arterial catheter were used for measurement of $\mathrm{pH}$ and blood gas tensions; the samples were placed on ice immediately and analyzed within $15 \mathrm{~min}$ on a blood gas analyzer (Corning Medical, Medfield, MA) after correcting for an assumed fetal temperature of $39^{\circ} \mathrm{C}$.

Experimental procedures. We studied the eight fetal sheep on 34 occasions (gestational ages 125 to $143 \mathrm{~d}$, estimated fetal weight 1.35 to $4.44 \mathrm{~kg}$ ), from 2 to $18 \mathrm{~d}$ after the operative procedure to allow recovery from surgery, for a total study time of $65.7 \mathrm{~h}$. Duration of each study period ranged from 0.8 to $4.0 \mathrm{~h}$. Each fetus was studied on at least two separate occasions and up to seven times in one fetus. During the studies, we continuously recorded systemic and pulmonary arterial blood pressures, heart rate, tracheal pressure, amniotic pressure, ECoG, and phasic and mean flow through the left pulmonary artery. Arterial blood samples for measurement of $\mathrm{pH}$ and blood gas tensions were obtained intermittently during the presence and absence of FBM and during LV-ECOG and HV-ECoG. The studies were repeated at frequent intervals until the ewe went into labor or the fetus died. After completion of the studies, the fetus and ewe were killed with separate injections of barbiturate. The fetus was weighed and examined to verify the positions of the catheters and flow transducer. At postmortem examination, the flow transducer and the tracheal and vascular catheters were confirmed to be in proper position in all fetuses. There was no fibrosis or constriction of the pulmonary artery present at autopsy for any fetus.

Analysis of data. For each study day, mean blood flow to the left lung (mean $\mathrm{Q}_{\mathrm{LPA}}$ ) was manually measured from the continuous recording of the left pulmonary artery blood flow every 60 $s$ of the study period according to the markings on the paper. FBM occur only during LV-ECoG; therefore, we separated the values for mean $\mathrm{Q}_{\mathrm{LPA}}$ into three categories: 1) LV-ECoG with FBM, 2) LV-ECoG without FBM, and 3) HV-ECoG (no FBM). Because the fetal weight and possibly fetal pulmonary blood flow increases as gestational age advances (9), the data were also corrected for estimated fetal weight to pool the data. The estimated fetal weights for each day of study were extrapolated from the data of Barcroft after drawing growth curves at different percentiles from the data (18). Using the known fetal weight and gestational age on the day of autopsy, the fetal weight at the day of study was then estimated from the percentile growth curve that correlated to the fetal weight at autopsy for that gestational age. For each individual study, the average and ranges of mean $\mathrm{Q}_{\mathrm{LPA}}$ (both as $\mathrm{mL} / \mathrm{min}$ and as $\mathrm{mL} / \mathrm{kg}$ of estimated fetal weight/ min) were calculated for each of these three categories, as well as for the total study that day. The heart rate and systemic and pulmonary blood pressures were also evaluated according to these three categories. Data were collected in each category for each fetal study.

Blood flow data from each fetus, as $\mathrm{mL} / \mathrm{min}$, and after correction for estimated fetal weight $(\mathrm{mL} / \mathrm{kg} / \mathrm{min})$ were analyzed for an effect of gestational age by regression analysis; overall, none was seen. Therefore, data from all studies for each fetus were pooled and an average value of mean $Q_{L P A}$ for each fetus was calculated for each of the three categories and for the entire study to adjust for the unequal number of studies done on the fetuses. Thus, each fetus carried equal weight in the final analyses.

We were also interested in evaluating whether changes in blood flow occurred during the onset or cessation of FBM or during changes in ECoG. We were interested in looking at all episodes in which changes occurred, as well as looking at sustained periods (at least $5 \mathrm{~min}$ ) of the presence or absence of FBM or changes in ECoG. We felt that these more sustained periods of FBM might cause an increase in pulmonary blood flow and thus be an important factor in lung growth. Therefore, we evaluated l) any changes in flow immediately after changes in FBM as well as changes in ECoG and 2) the effect of the onset or cessation of a longer period of FBM by comparing the average mean $\mathrm{Q}_{\mathrm{LPA}}$ for the 2-min period before with the 5-min period after the onset or cessation of FBM or changes in ECoG. This 5-min interval was selected to evaluate only the change in variables occurring around the sustained onset or cessation of FBM. A change in mean $Q_{L P A}$ of $10 \%$ or more from baseline was arbitrarily considered a "significant" change. Similar analyses of mean QLPA were performed for changes in ECoG.

Values for arterial $\mathrm{pH}$ and blood gas tensions were examined for differences between the presence or absence of FBM, and between LV- and HV-ECoG. We also examined phasic pulmonary blood flow for qualitative changes associated with FBM and compared these with changes in phasic systemic and pulmonary blood pressures.

Data were analyzed statistically using repeated measures analysis of variance for comparing all data among the three periods for each fetus (blood flow, heart rate and blood pressure, and arterial blood gases) and $\chi^{2}$ analysis for changes in FBM or ECoG (19). As noted above, regression analysis was used to compare blood flows over advancing gestational age. 


\section{RESULTS}

The clinical data for each fetus are shown in Table 1. Although there was a slight tendency in some fetuses for the total mean $Q_{L P A}$ to increase as the gestational age advanced (data not shown), this was an inconsistent finding in this study and was not significant, either individually (except in one fetus) or overall by regression analysis $\left(r^{2}=0.004\right)$. The mean $Q_{L P A}$ for each fetus was similar on each study day when corrected for the estimated fetal weight. The total mean $\mathrm{Q}_{\mathrm{LPA}}$ for all fetuses averaged $59 \pm 8$ $\mathrm{mL} / \mathrm{min}$ and was estimated as $25 \pm 4 \mathrm{~mL} / \mathrm{kg} / \mathrm{min}$ (mean \pm SEM).

Our study found that the presence of FBM did not cause an increase in the average mean $Q_{L P A}$ and was similar in both the presence and absence of FBM, and during both HV- and LVECoG (Table 2). FBM were present an average of $40 \%$ of the time; the ECoG showed low voltage activity $58 \%$ of the time and high voltage activity $42 \%$ of the time.

Although the presence or absence of FBM did not affect the average value of mean $Q_{L P A}$, there were significant changes in mean $Q_{L P A}$ associated with the sustained onset or occasion of FBM. The onset of FBM was associated with an increase in mean $Q_{\text {LPA }}$ significantly more frequently (Fig. 1, Table 3), and there were also significantly more episodes in which cessation of FBM was also associated with a decrease in mean $Q_{L P A}$. There were also significantly more episodes with a significant decrease in mean $Q_{L P A}$ with changes from LV- to HV-ECoG. However, there were no significant differences seen in mean $Q_{L P A}$ with changes from HV- to LV-W (Table 3). In contrast, it appeared that a sustained period of FBM or change in $\mathrm{ECOG}$ was required to alter blood flow; that is, when all episodes were considered, for the majority of the episodes no change in blood flow occurred (Table 3). These alterations in blood flow (both an increase and

Table 1. Gestational age, total average mean $Q_{L P A}$ and ranges of mean $Q_{L . P A}$, and length of study for each fetus*

Total mean

Total mean and range

Gestational and range of $\mathrm{Q}_{\mathrm{LPA}} / \mathrm{kg}$

Number age at of $\mathrm{Q}_{\text {LPA }}(\mathrm{mL} / \mathrm{kg} /$ Time studied

\begin{tabular}{|c|c|c|c|c|c|}
\hline Fetus & of studies & study (d) & $(\mathrm{mL} / \mathrm{min})$ & min) & (min) \\
\hline 1998 & 2 & $135.0 \pm 1.0$ & $\begin{array}{c}76.5 \pm 11.5 \\
(19-140)\end{array}$ & $\begin{array}{c}30.5 \pm 3.5 \\
(8-48)\end{array}$ & $146.0 \pm 17.0$ \\
\hline 2002 & 4 & $133.0 \pm 2.1$ & $\begin{array}{r}38.8 \pm 5.5 \\
(20-151)\end{array}$ & $\begin{array}{c}15.5 \pm 2.1 \\
(7-58)\end{array}$ & $142.0 \pm 46.5$ \\
\hline 3017 & 2 & $130.5 \pm 0.5$ & $\begin{array}{c}40.5 \pm 9.5 \\
(20-80)\end{array}$ & $\begin{array}{c}15.5 \pm 4.5 \\
(11-95)\end{array}$ & $91.0 \pm 20.0$ \\
\hline 3018 & 5 & $135.4 \pm 1.2$ & $\begin{array}{c}88.4 \pm 20.3 \\
(20-209)\end{array}$ & $\begin{array}{c}43.0 \pm 8.4 \\
\quad(11-95)\end{array}$ & $81.8 \pm 10.8$ \\
\hline 3127 & 5 & $136.4 \pm 1.9$ & $\begin{array}{c}28.0 \pm 1.4 \\
(20-39)\end{array}$ & $\begin{array}{c}18.2 \pm 1.0 \\
(12-26)\end{array}$ & $126.2 \pm 13.3$ \\
\hline 3128 & 3 & $128.3 \pm 1.5$ & $\begin{array}{c}64.0 \pm 14.5 \\
(21-109)\end{array}$ & $\begin{array}{c}36.7 \pm 6.7 \\
(13-59)\end{array}$ & $120.3 \pm 30.9$ \\
\hline 4359 & 7 & $129.4 \pm 1.2$ & $\begin{array}{r}89.4 \pm 9.2 \\
(20-241)\end{array}$ & $\begin{array}{c}31.4 \pm 2.8 \\
(8-83)\end{array}$ & $108.9 \pm 13.8$ \\
\hline 4367 & 6 & $130.5 \pm 0.8$ & $\begin{array}{c}45.3 \pm 2.3 \\
(20-99)\end{array}$ & $\begin{array}{c}12.7 \pm 0.9 \\
(5-31)\end{array}$ & $123.0 \pm 25.2$ \\
\hline
\end{tabular}

* Data are mean \pm SEM. a decrease with changes in FBM or ECoG) were seen in seven of the eight fetuses; one fetus had only an increase in mean $Q_{\text {LPA }}$ with the onset of sustained FBM.

The heart rate during HV-ECoG was significantly higher than during periods of LV-ECoG, both with and without FBM (Table 4). There were no changes in mean systemic or pulmonary arterial blood pressures during these time periods (Table 4). Systemic blood pressure was consistently below pulmonary arterial blood pressure.

Fetal arterial $\mathrm{pH}$ and blood gas tensions were within normal ranges except for one fetus with a $\mathrm{PCO}_{2}$ of $7.6 \mathrm{kPa}$ and a normal $\mathrm{pH}$ (7.34). This fetus did not have an increased incidence of FBM $(47 \%)$ or differences in mean $Q_{\mathrm{LPA}}$ with FBM and thus was included in the final analysis. The fetal arterial $\mathrm{pH}$ and blood gas tensions did not differ between periods of presence or absence of FBM or between different ECoG states (Table 4).

We also examined the effects of FBM on phasic (beat to beat) pulmonary blood flow. With FBM, each inspiratory effort was associated with a small increase in peak phasic pulmonary blood flow; the expiratory phase was associated with a decrease in flow (Fig. 2). This change was not quantifiable and is only a qualitative assessment of the left pulmonary artery blood flow tracing. The breathing movements were associated with changes in the opposite direction (i.e. a decrease during the inspiratory phase and an increase during the expiratory phase) in systolic and diastolic blood pressures (both systemic and pulmonary). During periods of no FBM, there were no beat to beat changes in peak phasic pulmonary blood flow or in systemic or pulmonary arterial blood pressures.

In each fetus, mean $Q_{L P A}$ showed wide variation during each study; the total range was $20-241 \mathrm{~mL} / \mathrm{min}$ and $7-95 \mathrm{~mL} / \mathrm{kg}$ / min (Table 1). Similar ranges were seen for each fetus during each study in each of the three periods (data not shown). In particular, the period of FBM did not have a higher range of mean $Q_{L P A}$ than the other periods. These variations in mean $\mathrm{Q}_{\mathrm{LPA}}$ occurred independent of gestational age, FBM, and ECoG and without changes in arterial $\mathrm{pH}$ or blood gas tensions.

\section{DISCUSSION}

The purpose of this study was to test the hypothesis that normally occurring intermittent FBM cause associated intermittent increases in mean blood flow to the lungs. Our study of fetal sheep during late gestation showed that the average mean pulmonary blood flow to the left lung did not increase during periods of FBM. Although we noted an increased incidence of an increase in mean pulmonary blood flow at the onset of sustained periods of FBM and an increased incidence of a decrease in mean pulmonary blood flow at the onset of sustained cessation of periods of FBM, these changes were of brief duration and occurred in less than $50 \%$ of the episodes. This finding did not persist when all episodes were considered. Therefore, our results indicate that normally occurring intermittent FBM do not have a consistent influence on mean pulmonary blood flow.

In fetal sheep, the left lung composes approximately $40 \%$ of the total lung weight (20). If we assume that the left lung receives $40 \%$ of total blood flow to the lung, then total pulmonary blood flow in our study would be about $63 \mathrm{~mL} / \mathrm{kg} / \mathrm{min}$; this value is within the ranges previously reported for pulmonary blood flow

Table 2. Mean $Q_{L P A}$ during $L V-E C o G$ (with and without FBM) and during $H V-E C o G^{*}$

\begin{tabular}{lcccc}
\hline & $\begin{array}{c}\text { Total } \\
\text { study period }\end{array}$ & $\begin{array}{c}\text { LV-ECOG } \\
\text { with FBM }\end{array}$ & $\begin{array}{c}\text { LV-ECoG } \\
\text { without FBM }\end{array}$ & $\begin{array}{c}\text { HV-ECOG } \\
\text { without FBM }\end{array}$ \\
\hline Time of study (\%) & 100 & $40 \pm 3$ & $18 \pm 3$ & $42 \pm 2$ \\
Mean QtPA & & $61 \pm 9$ & $57 \pm 8$ & $57 \pm 7$ \\
Average (mL/min) & $59 \pm 8$ & $25 \pm 4$ & $24 \pm 4$ & $24 \pm 3$ \\
Average (mL/kg/min) & $25 \pm 4$ & & & \\
\hline
\end{tabular}

* Data are mean \pm SEM. None of the differences between groups for blood flow were significant by analysis of variance. 

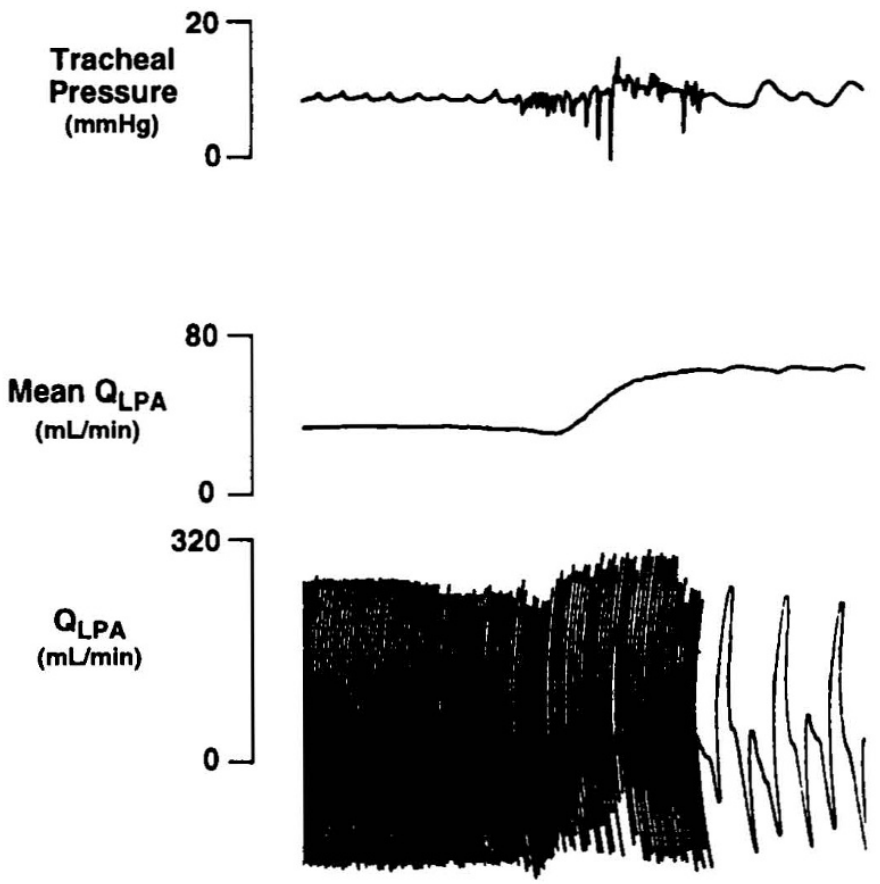

Fig. 1. An episode of increased mean and phasic left pulmonary artery blood flow seen with the onset of FBM in a fetal sheep at $138 \mathrm{~d}$ of gestation.

Table 3. Changes in mean $Q_{L P A}$ with changes in FBM and $E C o G^{*}$

\begin{tabular}{llll}
\hline & \multicolumn{3}{c}{$\begin{array}{c}\text { Changes in flow (number of } \\
\text { episodes) }\end{array}$} \\
\cline { 2 - 4 } & Increase & No change & Decrease \\
\hline Sustained episodes & $37 \dagger$ & 34 & 14 \\
Onset of FBM $(n=85)$ & 14 & 29 & $39 \ddagger$ \\
Cessation of FBM $(n=82)$ & 18 & 30 & 15 \\
HV-ECoG to LV-ECoG $(n=63)$ & 11 & 27 & $25 \S$ \\
LV-ECoG to HV-ECoG $(n=63)$ & 11 & & \\
All episodes & 59 & $102 \|$ & 23 \\
Onset of FBM $(n=184)$ & 28 & $98 \|$ & 55 \\
Cessation of FBM $(n=181)$ & 29 & $80 \|$ & 28 \\
HV-ECoG to LV-ECoG $(n=137)$ & 29 & $51 \|$ & 26 \\
LV-ECoG to HV-ECoG $(n=99)$ & 22 & \\
\hline
\end{tabular}

* Changes in flow were considered significant if they were at least $10 \%$ different (increased or decreased) from the average mean $Q_{L P A}$ on that study day. Sustained episodes of at least $5 \mathrm{~min}$ duration and all episodes were considered. For the sustained episodes, there were more episodes during the onset of FBM in which the mean $Q_{L P A}$ increased, and more episodes during the cessation of FBM in which the $Q_{L P A}$ decreased. There were also more episodes from LV-ECoG to HV-ECoG in which the flow decreased. For all episodes, there were significantly more episodes in which flow did not change, either during the onset or cessation of FBM or during changes in ECoG.

$+\chi^{2}=11.05, p=0.004$.

$\ddagger \chi^{2}=11.60, p=0.003$.

$\S \chi^{2}=7.24, p=0.03$.

$\| p<0.0006$.

as measured with radioactive microspheres $(20,21)$ or electromagnetic flow transducers (9) in fetal sheep. Although the flow transducer caused a small constriction of the left pulmonary artery that reduced its cross-sectional area to no less than $90 \%$ of normal, it is unlikely that this affected blood flow to that lung. In a previous study in fetal sheep, we showed that narrowing the left pulmonary artery to $25 \%$ of its normal cross-sectional area has no effect on blood flow to the left lung (22).

Our results during normal fetal conditions are in contrast to what occurs during abnormal fetal conditions such as acidosis. Respiratory or metabolic acidosis increases pulmonary blood flow in fetal sheep (13) and stimulates FBM of increased magnitude $(10,11,23)$. In our study, there were no significant changes in fetal arterial $\mathrm{pH}$ or $\mathrm{PCO}_{2}$ during $\mathrm{FBM}$, and they remained within normal limits at all times.

FBM normally occur only during LV-ECoG, and we considered the possibility that central mechanisms associated with changes in ECoG might influence pulmonary blood flow. However, our data indicate that pulmonary blood flow is similar during both LV- and HV-ECoG. Our results are similar to those of Jensen et al. (21), who used a radioactive microsphere method to examine the effects of changes in ECoG on distribution of cardiac output in fetal sheep. Although they detected changes in regional brain blood flow, they found no changes in pulmonary blood flow with changes in ECoG. We also did not find a consistent change in pulmonary blood flow associated with changes in ECoG.

With postnatal breathing, pulmonary blood flow increases during the inspiratory phase secondary to the decrease in intrathoracic pressure and the resultant increase in venous return to the chest (14). Our studies show similar results in utero: during FBM, a small increase in phasic pulmonary blood flow occurs during the inspiratory phase when the intrathroacic pressure falls, and a decrease in pulmonary blood flow occurs during the expiratory phase. These changes are probably due to the effects of alterations in intrathoracic pressure on venous return, which are similar in the fetal lamb and in the postnatal state (24). However, as noted above, there were no changes in mean pulmonary blood flow during FBM despite these small changes in phasic flow. As previously noted by Fouron et al. (25), we also found a decrease in systemic arterial blood pressures during the inspiratory phase of FBM; in addition, we documented a similar decrease in pulmonary arterial blood pressures during the inspiratory phase. In this study, mean pulmonary blood pressure was consistently higher than systemic pressure, similar to the finding previously reported by Heymann and Rudolph (26). It is interesting to note that the onset of FBM did not cause a significant decrease in pulmonary arterial pressure to subsystemic levels, which occurs with the onset of postnatal breathing.

Previous authors (25) have shown increases in heart rate and blood pressure associated with the onset of FBM. In contrast to this, we did not find a difference in heart rate or blood pressure when evaluating the entire period of FBM. Although we also noted occasional tachycardia and hypertension with the onset of FBM, these changes were transient and occurred only during the first few minutes of the periods of FBM. In our study, periods of FBM occasionally lasted 15 to $30 \mathrm{~min}$. In addition, although the fetal heart rate in our study was higher during HV-ECoG, this did not seem to be related to the absence of FBM, inasmuch as the heart rate during LV-ECoG was similar in the presence and absence of FBM.

The presence of wide variations in mean $Q_{L P A}$ was a surprising finding and, to our knowledge, has not been reported previously. These variations were noted in all the fetuses, were unrelated to gestational age, and occurred in the absence of changes in arterial $\mathrm{pH}$ and blood gas tensions and independent of the presence or absence of FBM and type of ECoG. It is unlikely that these variations in mean $Q_{L P A}$ were artifacts for the following reasons: 1) the variations occurred in all eight fetuses; 2) they were not associated with maternal movements or with fetal movements that could be detected by observation of the maternal abdominal wall; 3) zero flow was checked frequently and showed very little drift; and 4) the flow transducer was sutured firmly in place and was in proper position at postmortem examination of the fetus. Additional studies are required to determine the causes of the fluctuation in pulmonary blood flow in the fetus.

We conclude that spontaneously occurring intermittent breathing movements in fetal sheep are not associated with consistent changes in mean pulmonary blood flow; therefore, we 
Table 4. Heart rate, pulmonary and systemic arterial blood pressures, and arterial pH and blood gas tensions during LV-ECoG (with and without FBM) and during $H V-E C o G^{*}$

\begin{tabular}{|c|c|c|c|}
\hline & $\begin{array}{c}\text { LV-ECoG with } \\
\text { FBM } \\
\end{array}$ & $\begin{array}{c}\text { LV-ECoG without } \\
\text { FBM }\end{array}$ & $\begin{array}{c}\text { HV-ECoG without } \\
\text { FBM } \\
\end{array}$ \\
\hline Heart rate (beats/min) & $176 \pm 5$ & $177 \pm 6$ & $186 \pm 6 \dagger$ \\
\hline Mean pulmonary arterial blood pressure $(\mathrm{mm} \mathrm{Hg}$ ) & $45 \pm 3$ & $44 \pm 3$ & $46 \pm 3$ \\
\hline Mean systemic arterial blood pressure $(\mathrm{mm} \mathrm{Hg})$ & $40 \pm 2$ & $39 \pm 1$ & $40 \pm 1$ \\
\hline Arterial pH & $7.36 \pm 0.01$ & $7.35 \pm 0.01$ & $7.36 \pm 0.01$ \\
\hline Arterial $\mathrm{PCO}_{2}[\mathrm{kPa}(\mathrm{mm} \mathrm{Hg})]$ & $6.5 \pm 0.3(49 \pm 2)$ & $6.4 \pm 0.3(48 \pm 2)$ & $6.5 \pm 0.3(49 \pm 2)$ \\
\hline Arterial $\mathrm{PO}_{2}[\mathrm{kPa}(\mathrm{mm} \mathrm{Hg})]$ & $2.9 \pm 0.3(22 \pm 2)$ & $2.8 \pm 0.3(21 \pm 2)$ & $2.9 \pm 0.1(22 \pm 1)$ \\
\hline
\end{tabular}

* Data are mean \pm SEM. There were no differences between any of the periods for blood pressure, arterial pH, or arterial blood gases.

$\dagger p=0.01$, HV-ECoG without FBM $v s$ LV-ECoG with FBM and LV-ECoG without FBM.

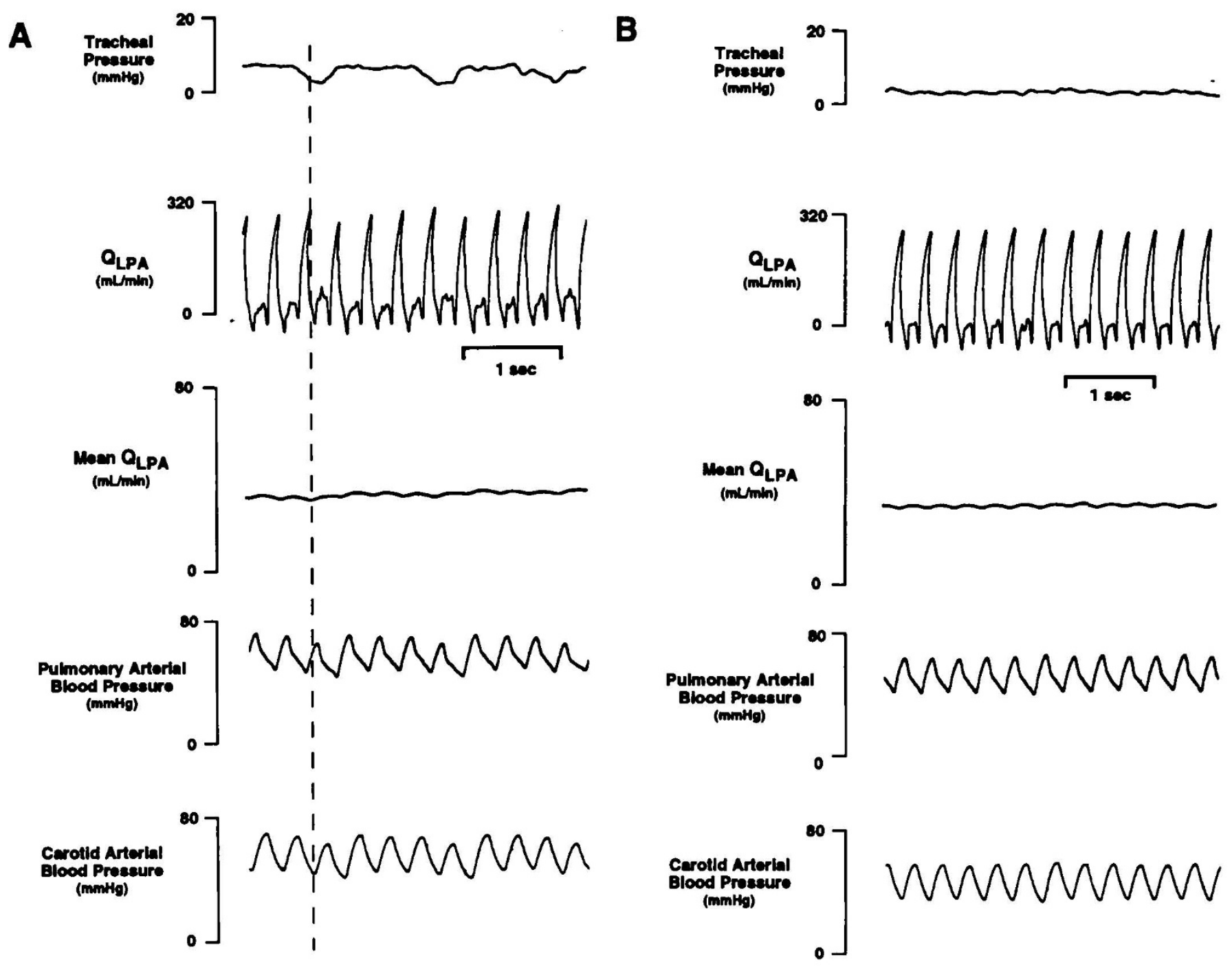

Fig. 2. Relationship of FBM to phasic pulmonary arterial blood flow and phasic pulmonary blood pressure during periods of FBM $(A)$ and no FBM $(B)$. Note that during the inspiratory phase (vertical line at negative tracheal pressure deflection) phasic peak pulmonary blood flow increases and phasic pulmonary arterial blood pressure (systolic and diastolic) decrease. No such fluctuations are seen during the absence of FBM.

think it is unlikely that FBM stimulate fetal lung growth through changes in pulmonary blood flow. However, FBM do cause small changes in phasic pulmonary blood flow similar to those seen during postnatal breathing.

\section{REFERENCES}

1. Alcorn D, Adamson TM, Maloney JE, Robinson PM 1980 Morphological effects of chronic bilateral phrenectomy or vagotomy in the fetal lamb lung. J Anat 130:683-695

2. Fewell JE, Lee C.CH, Kitterman JA 1981 Effects of phrenic nerve section on the respiratory system of fetal lamb. J Appl Physiol 51:293-297

3. Liggins GC, Vilos GA, Campos GN, Kitterman JA, Lee CH 1981 The effect of spinal cord transection on lung development in fetal sheep. J Dev Physiol 3:267-274

4. Wigglesworth JS, Desai R 1979 Effects on lung growth of cervical cord section in the rabbit fetus. Early Hum Dev 3:51-65

5. Wallen LD, Perry SF, Alston JT, Maloney JE 1990 Morphometric study of the role of pulmonary arterial flow in fetal lung growth in sheep. Pediatr Res 27:122-127

6. Clewlow F, Dawes GS, Johnston BM, Walker DW 1983 Changes in breathing. electrocortical and muscle activity in unanaesthetized fetal lambs with age. J Physiol (Lond) 341:463-476

7. Maloney JE, Adamson TM, Brodecky V, Dowling MH, Ritchie BC 1975 Modification of respiratory center output in the unanesthetized fetal sheep "in utero." J Appl Physiol 39:552-558

8. Cohn HE, Sacks EJ, Heymann MA, Rudolph AM 1974 Cardiovascular re- 
sponses to hypoxemia and acidemia in fetal lambs. Am J Obstet Gynecol 120:817-824

9. Lewis AB, Heymann MA, Rudolph AM 1976 Gestational changes in pulmonary vascular responses in fetal lambs in utero. Circ Res 39:536-541

10. Bowes G, Wilkinson MH, Dowling M. Ritchie BC. Brodecky V, Maloney JE 1981 Hypercapnic stimulation of respiratory activity in unanesthetized fetal sheep in utero. J Appl Physiol 50:701-708

11. Chapman RLK. Dawes GS, Rurak DW, Wilds PL 1980 Breathing movements in fetal lambs and the effect of hypercapnia. J Physiol (Lond) 302:19-29

12. Jansen AH, Russell BJ. Chernick V 1982 Influence of sleep state on the response to hypercapnia in fetal lambs. Respir Physiol 48:125-142

13. Rosenberg AA, Koehler RC, Jones Jr MD 1984 Distribution of cardiac output in fetal and neonatal lambs with acute respiratory acidosis. Pediatr Res 18:731-735

14. Brecher GA 1955 Pulmonary blood flow and venous return during spontaneous respiration. Circ Res 3:210-214

15. Kitterman JA, Liggins GC, Fewell JE, Tooley WH 1983 Inhibition of breathing movements in fetal sheep by prostaglandins. J Appl Physiol 54:687-692

16. Dawes G, Fox H, Leduc B, Liggins G, Richards R 1972 Respiratory movements and rapid eye movement sleep in the foetal lamb. J Physiol 220:119-143
17. Ruckebusch Y 1972 Development of sleep and wakefulness in the foetal lamb. Electroencephalogr Clin Neurophysiol 32:119-128

18. Barcroft J 1946 Researches on Pre-Natal Life. Thomas, Springfield, IL, p 33

19. Zar JH 1984 Biostatistical Analysis. Prentice-Hall, Englewood Cliffs, NJ

20. Rudolph AM, Heymann MA 1970 Circulatory changes during growth in the fetal lamb. Circ Res 26:289-299

21. Jensen A, Bamford OS, Dawes GS, Hofmeyr G, Parkes MJ 1986 Changes in organ blood flow between high and low voltage electrocortical activity in fetal sheep. J Dev Physiol 8:187-194

22. Guerra FA, Savich RD, Lee CH, Kitterman JA 1988 Effects of left pulmonary artery stenosis on lung growth in fetal sheep. Clin Res 36:241A(abstr)

23. Molteni RA, Melmed MH, Sheldon RE, Jones MD, Meschia G 1980 Induction of fetal breathing by metabolic acidemia and its effect on blood flow to the respiratory muscles. Am J Obstet Gynecol 136:609-620

24. Reuss ML, Rudolph AM, Dae MW 1983 Phasic blood flow patterns in the superior and inferior venae cavae and umbilical vein of fetal sheep. Am J Obstet Gynecol 145:70-78

25. Fouron J-C, Korcaz Y, Leduc B 1975 Cardiovascular changes associated with fetal breathing. Am J Obstet Gynecol 123:868-876

26. Heymann MA, Rudolph AM 1976 Effects of acetylsalicylic acid on the ductus arteriosus and the circulation in fetal lambs in utero. Circ Res 38:418-422 